\title{
ADRENAL FAILURE DUE TO BILATERAL SUPRARENAL INFARCTION ASSOCIATED WITH SYSTEMIC NODULAR PANNICULITIS AND ENDARTERITIS
}

\author{
BY \\ M. S. R. HUTT AND J. L. PINNIGER \\ From the Louis Jenner Laboratory, St. Thomas's Hospital, London
}

(RECEIVED FOR PUBliCATION JANUARY 20, 1956)

\begin{abstract}
Although involvement of the periadrenal vessels is frequent in cases of hypersensitivity angiitis or polyarteritis nodosa, it rarely results in clinical adrenal insufficiency. The present case is reported, first because infarction of the suprarenals led to this clinical state, and secondly because of the unusual and complex nature of the underlying pathological process.
\end{abstract}

\section{Case Report}

Mr. C. B., aged 49, was admitted to hospital on July 21,1954 , complaining of continuous abdominal pain and vomiting for two days. The patient had been under treatment since 1951 for pulmonary tuberculosis, and was receiving streptomycin and P.A.S. at the time of his admission; there had been no recent evidence of activity of the lung lesion. $\mathrm{He}$ had been admitted to hospital in January, 1954, complaining of abdominal pain for 11 days, and was found at operation to have a perforation of the small bowel. This was sutured and an end-to-end anastomosis of the bowel was performed. The histological report was as follows:

"Chronic inflammation of the wall of the small intestine, with superadded acute inflammation and peritonitis. A regional lymph node shows chronic inflammation. No specific inflammatory features."

Following this operation the patient made an uneventful recovery, but about three months before the present admission he began to complain of vague abdominal pain in the right iliac fossa and right loin associated with occasional vomiting. Two days before admission this pain became continuous and he vomited after all food. On examination the patient showed tenderness and guarding in the right iliac fossa and hypochondrium and a continued pyrexia.

Laboratory Findings (July 22, 1954).-Haemoglobin, $100 \%$ (Haldane); W.B.C., 4,200/c.mm. (neutrophils $55 \%$, lymphocytes $28 \%$, monocytes $3 \%$, eosinophils $11 \%$, basophils $3 \%$ ). A urine examination gave protein ++ , mucus + , red blood cells +++ , moderate numbers of white blood cells and epithelial cells, but no casts. Plasma electrolytes (mEq./1.) Na 134, $\mathrm{K} 5.1, \mathrm{Cl} 90.5, \mathrm{CO}_{2} 23.2$, blood urea $38 \mathrm{mg}$ \% .
Progress.-The patient's abdominal pain and fever continued over the next few days with occasional vomiting. There was progressive depletion of sodium and chloride ions despite the administration of large amounts of sodium chloride and lactate, both intravenously and by mouth. This loss was associated with a good urinary output $(1,000$ to $1,800 \mathrm{ml}$.) and high urinary chlorides (3-4 g./1.). Further investigations included intravenous and retrograde pyelograms, both of which appeared normal, though during the latter blood-stained urine was seen coming from both ureteric orifices. A barium meal was also normal. On July 29, 1954, the patient developed discrete indurated macules on the trunk, and a biopsy of one of these showed infarction of the skin and focal inflammatory cell infiltration of the subcutaneous fat. He continued to have severe abdominal pain and vomiting, and the blood urea level had now risen to $64 \mathrm{mg} . \%$. Treatment with antituberculosis drugs, streptomycin and I.N.H., and later with terramycin, had no effect on the fever. By August 3 the patient's blood pressure had fallen to $80 / 60 \mathrm{~mm}$. $\mathrm{Hg}$, the macular rash was beginning to fade, and the patient showed increasing weakness and apathy. As can be seen in the accompanying Table, intravenous therapy

TABLE

PLASMA ELECTROLYTES (mEq/litre)

\begin{tabular}{|c|c|c|c|c|c|}
\hline Date & $\mathrm{Na}^{+}$ & $\mathbf{K}^{+}$ & $\mathrm{Cl}^{-}$ & $\mathrm{HCO}_{3}^{-}$ & $\begin{array}{c}\text { Blood Urea } \\
\text { (mg.\%) }\end{array}$ \\
\hline $\begin{array}{r}22.7 .55 \\
23.7 .55 \\
3.8 .55 \\
5.8 .55 \\
7.8 .55\end{array}$ & $\begin{array}{l}134 \\
130 \\
103 \\
125 \\
118\end{array}$ & $\begin{array}{l}5 \cdot 1 \\
4.6 \\
5.8 \\
4.6 \\
4.9\end{array}$ & $\begin{array}{c}90 \cdot 5 \\
84 \cdot 5 \\
72 \\
100 \\
87\end{array}$ & $\begin{array}{l}23 \cdot 2 \\
19 \\
13 \\
17 \cdot 5\end{array}$ & $\begin{array}{l}38 \\
64\end{array}$ \\
\hline
\end{tabular}

had little effect in raising the serum electrolytes throughout his illness. The patient's condition deteriorated steadily, and on August 6 he showed signs of over-hydration with ankle oedema and basal crepitations. He died on the following day, 18 days after admission to hospital.

The association of fever and haematuria, together with evidence of renal impairment and the abnormal electrolyte findings, suggested clinically 
that this patient had a renal lesion with a tubular defect resulting in salt loss. Adrenal failure due to Addison's disease was considered, but was thought unlikely in view of the short history, absence of pigmentation, and associated findings such as haematuria and the rash. Cortisone was started 24 hours before death, but no further investigations were carried out after its administration.

\section{Necropsy}

Necropsy was performed on August 9, 1954.

The body was that of a middle-aged man showing marked oedema of the legs and back, and an occasional small area of pigmentation on the trunk.

Cardiovascular System.-The pericardial sac, heart muscle, and valves appeared normal. The coronary arteries and large vessels were mildly atheromatous.

Respiratory System.-Approximately $200 \mathrm{ml}$. of straw-coloured fluid was present in each pleural sac. The trachea and main bronchi contained a little mucopus, and both lungs were markedly oedematous, particularly at the bases. There was a cavity, $1 \mathrm{~cm}$. in diameter, in the apex of the left lower lobe, having a firm, well-defined fibrous wall and containing caseous material.

Alimentary System and Other Intra-abdominal Organs.-The oesophagus and stomach were normal. There was a nodule of white tissue, approximately $2.5 \mathrm{~cm}$. in diameter, on the anterior surface of the first part of the duodenum, which was slightly raised above the peritoneal surface, but which did not involve the mucous membrane. Some small superficial ulcers were present in the mucous membrane of this part of the duodenum. The rest of the small bowel was normal apart from the scar of an anastomosis $15 \mathrm{~cm}$. from the beginning of the jejunum. The large bowel was normal. Enlarged soft lymph nodes of up to $2 \mathrm{~cm}$. in diameter were present around the aorta, the coeliac axis, and the splenic hilum. The liver was of normal size, but was pale and appeared to be slightly firmer than normal. The gall bladder and pancreas were normal.

The spleen was enlarged approximately to twice its normal size and the splenic pulp was very soft. The adrenal glands were fixed to the surrounding tissues by young vascular connective tissue which extended on to the surface of both kidneys. On section the normal anatomical outlines were seen to be present, but the cortices were very pale and firm apart from a small haemorrhagic area in the right adrenal.

The kidneys were congested but were otherwise normal. The pelvis of the right kidney showed several small submucous haemorrhages. The renal vessels appeared normal. The urinary bladder showed evidence of a recent cystitis.

Bone Marrow.-This was not examined.

\section{Histology}

Small Bowel.-The biopsy section taken at the site of perforation shows a severe chronic inflammation throughout, part of the perforation wall being lined by granulation tissue. The inflammatory reaction is not specific, but in the fatty tissue foci are present where there is degeneration of the fat cells, associated with a histiocytic and giant cell reaction. Many of the histiocytes appear to be stretched over the surface of intact fat cells (Fig. 1). Some of the larger arteries and veins show narrowing of their lumina by a loose connective tissue in the intima, and the arteries are permeated with fibrin in the region of the internal elastic lamina (Fig. 2).

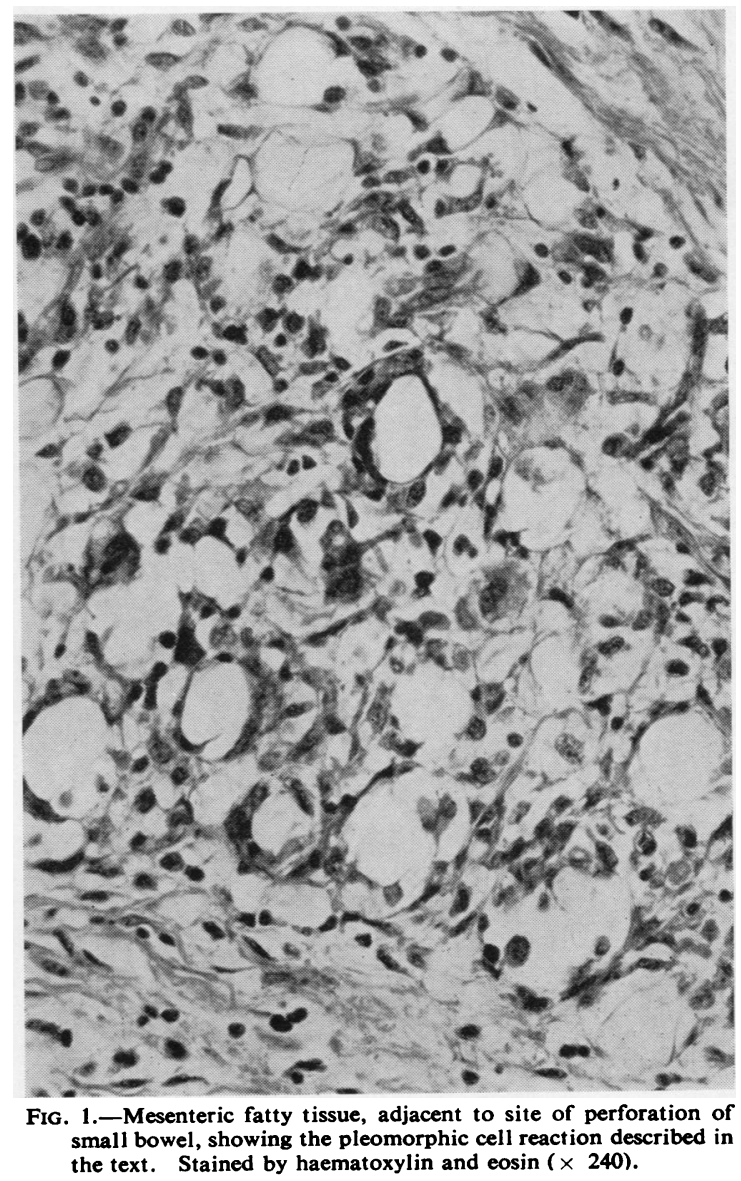


Skin.-The biopsy shows that there is infarction of skin leading to necrosis of epidermis and accessory skin structures in the dermis, and secondary infection of the ulcerated surface (Fig. 3). Foci are present in the underlying subcutaneous fatty tissue showing similar changes to those described for the small bowel. No vascular changes can be identified.

Adrenals. - There is widespread necrosis in both adrenals, taking the form of coalescing infarcts, with intervening small islands of surviving, though degenerate, cortical tissue. The necrotic tissue is heavily infiltrated with fibrin and red blood cells and includes a number of thrombosed blood vessels. The periadrenal connective tissue contains an abundant cellular exudate (Fig. 4). These cells are predominantly histiocytes, lymphocytes, and granulocytes ; a smaller number of

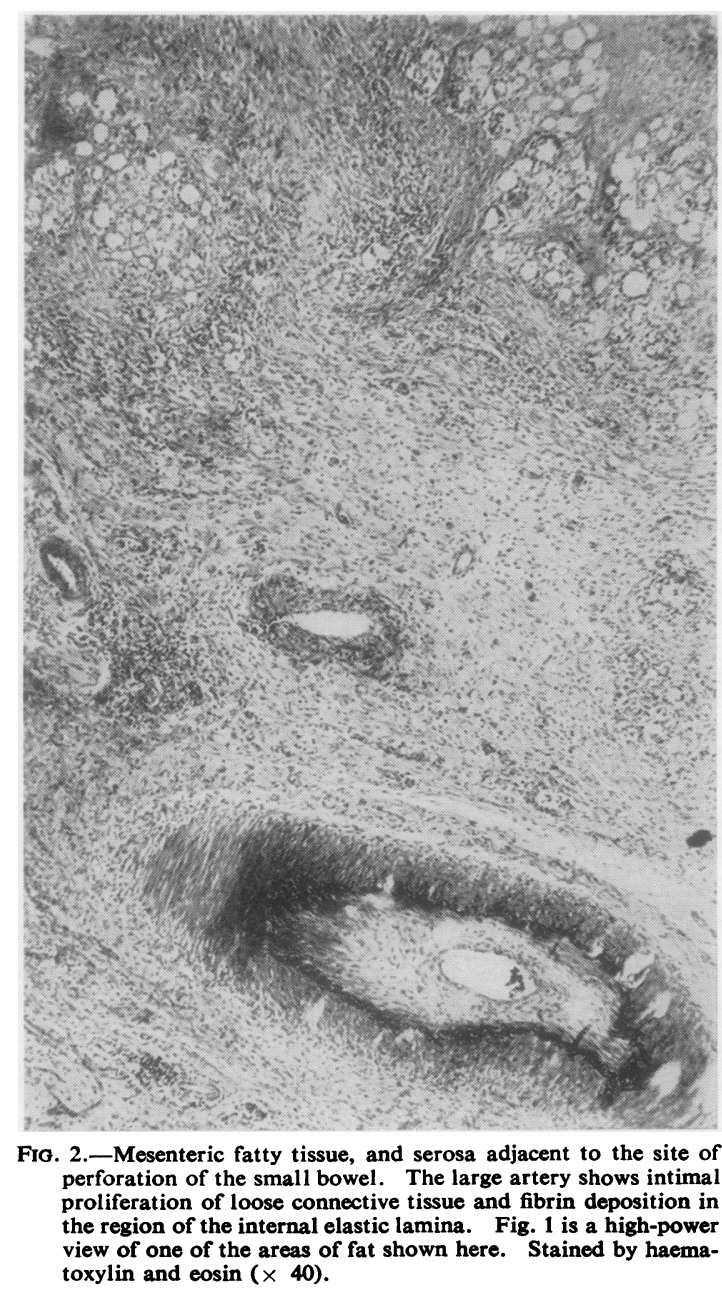

FIG. 2.-Mesenteric fatty tissue, and serosa adjacent to the site of perforation of the small bowel. The large artery shows intimal proliferation of loose connective tissue and fibrin deposition in the region of the internal elastic lamina. Fig. 1 is a high-power view of one of the areas of fat shown here. Stained by haematoxylin and eosin $(\times 40)$.

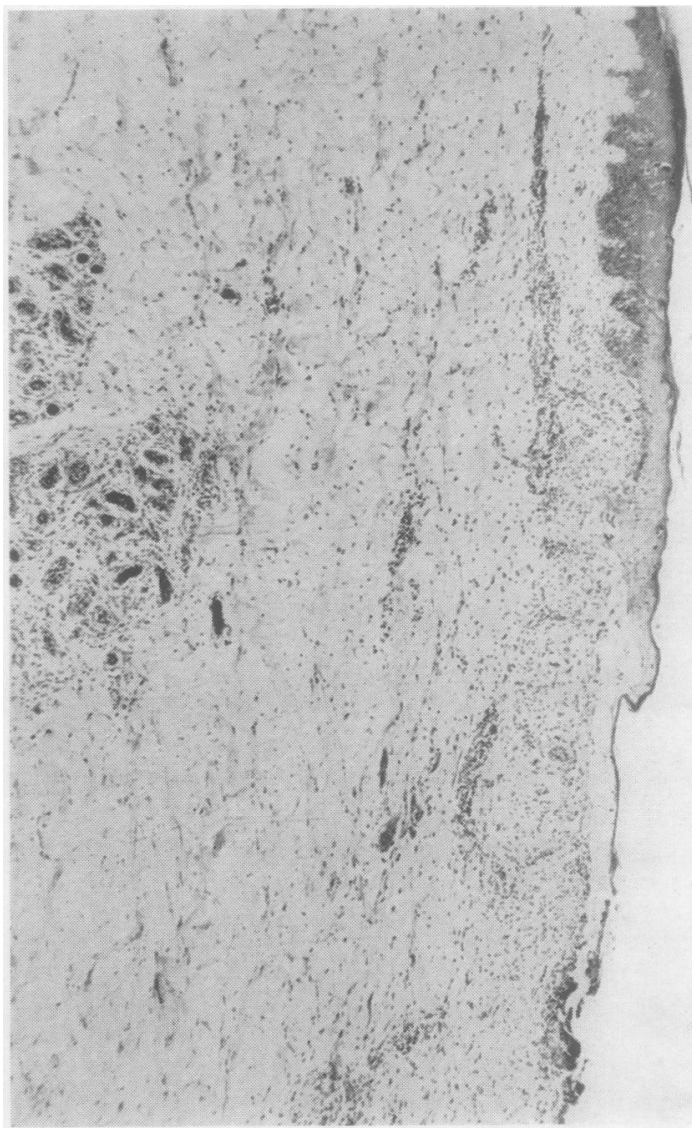

FIG. 3.-Skin which includes part of an area of infarction. Stained by haematoxylin and eosin $(\times 40)$.

multinucleate giant cells are also present. Here and there degenerative changes are present in the fatty tissue which are associated with a histiocytic reaction, including "foam" cells. There is deposition of fibrin on the intimal surfaces of many of the arteries and veins in the periadrenal fatty tissue, and in the case of some of the arteries it has permeated into the wall. In the latter instances the intima is thickened through the formation of a loose connective tissue (Fig. 5), but this proliferation is frequently present in the absence of fibrin deposition. Some of the larger arteries show necrosis of their walls associated with an inflammatory cell infiltration, the supporting connective tissue being still apparently healthy, apart from the presence of inflammatory cells. No thromboses could be seen in any of the vessels, except those within the infarcted adrenals.

Lymph Nodes.-Three nodes were examined. The general architecture has been partially obliterated in two of them. All show sinusoidal 


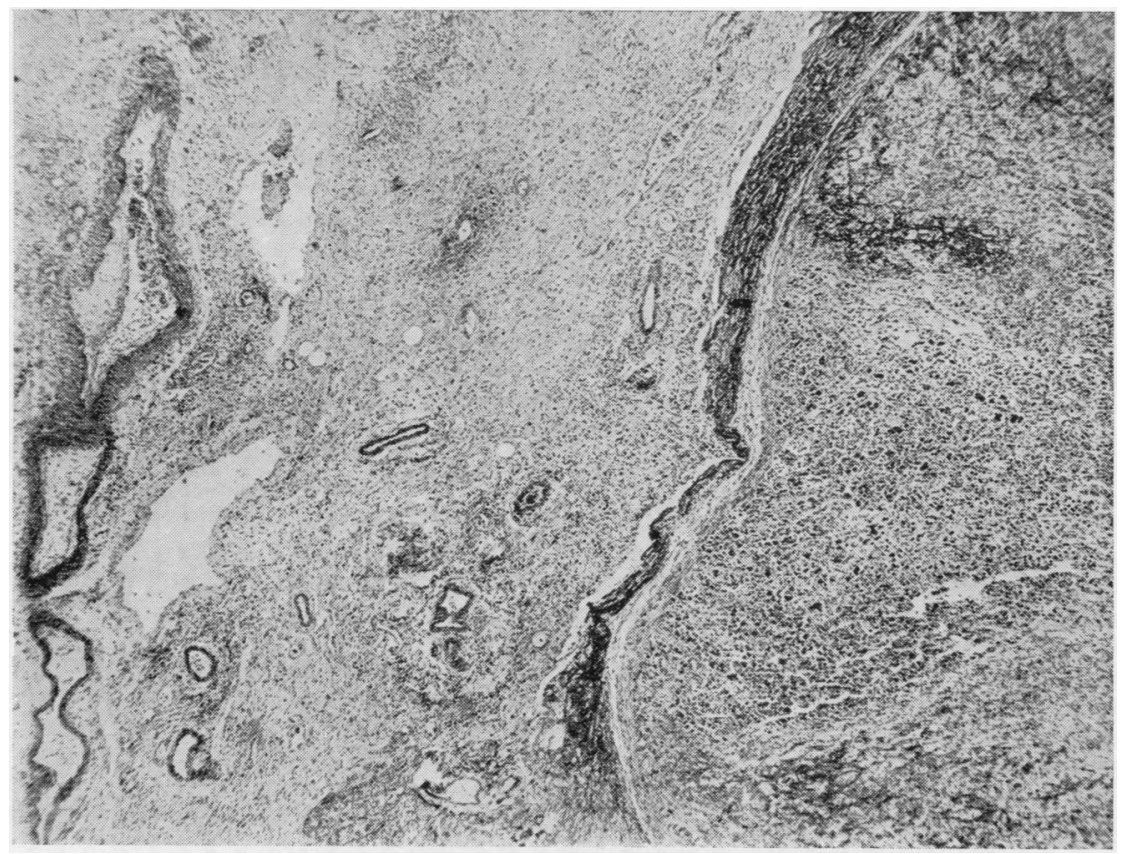

FIG. 4.-Section showing necrotic adrenal with chronic inflammation and endarteritic thickening in periadrenal fatty tissue. Stained by haematoxylin and eosin $(x 30)$.

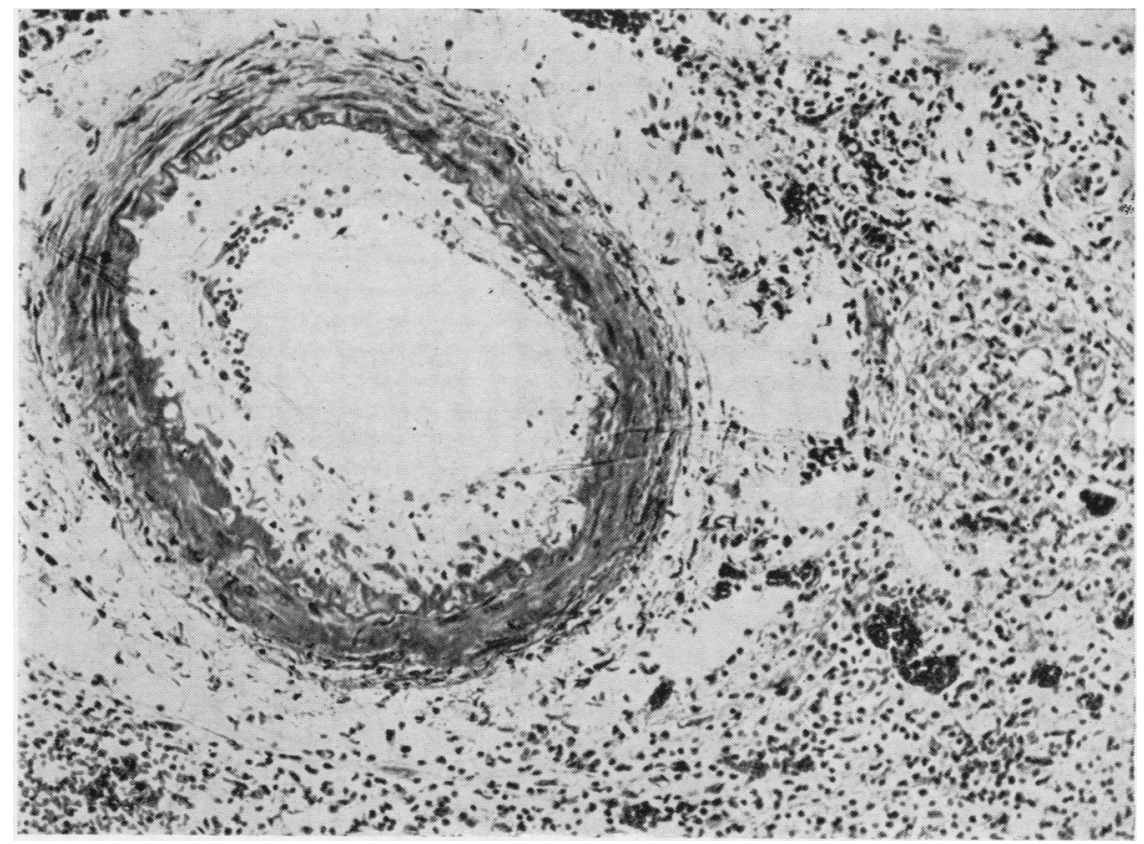

FIG. 5.-Artery in periadrenal tissue showing narrowing of lumen by loose connective tissue and deposition of fibrin in the region of the internal olastic lamina. Stained by haematoxylin and eosin $(\times 140)$. 


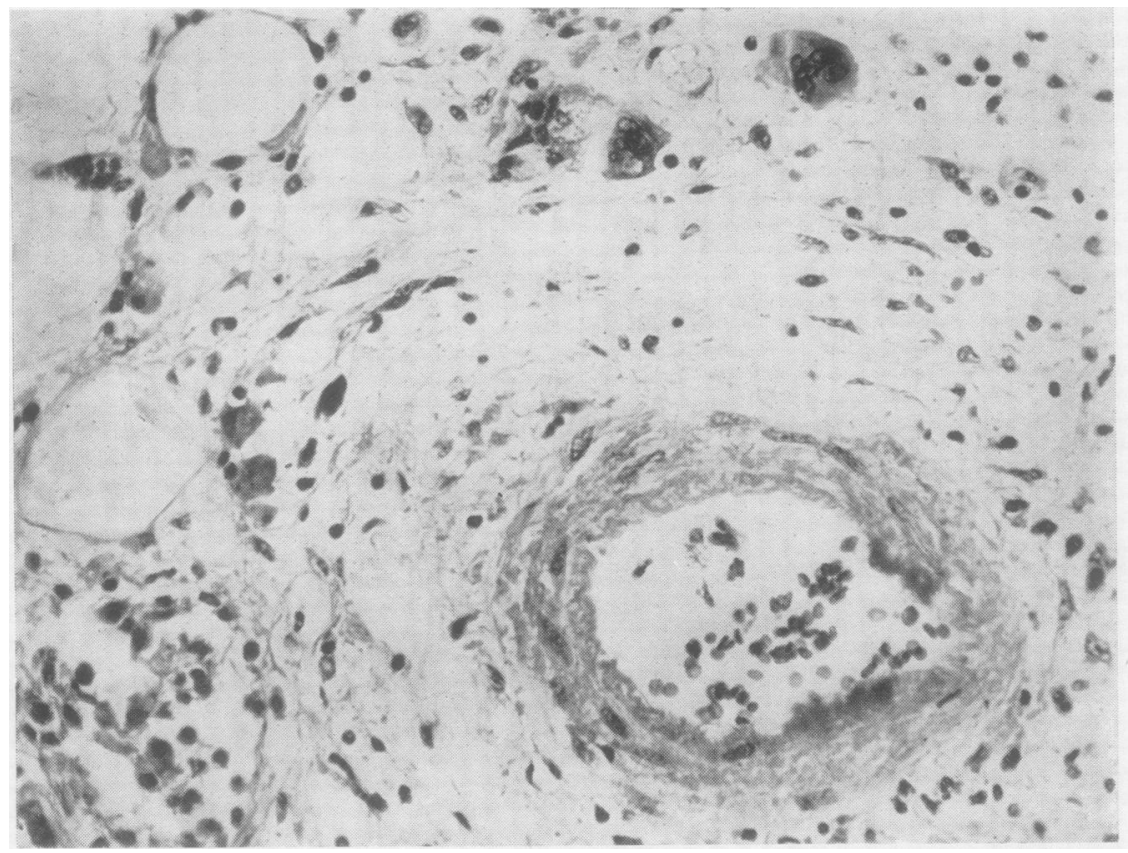

Fig. 6.-Epicardial fatty tissue showing pleomorphic cellular reaction with giant cells, and containing a small artery with a deposit of fibrin on the intimal surface. Stained by haematoxylin and $\operatorname{cosin}(\times 240)$.

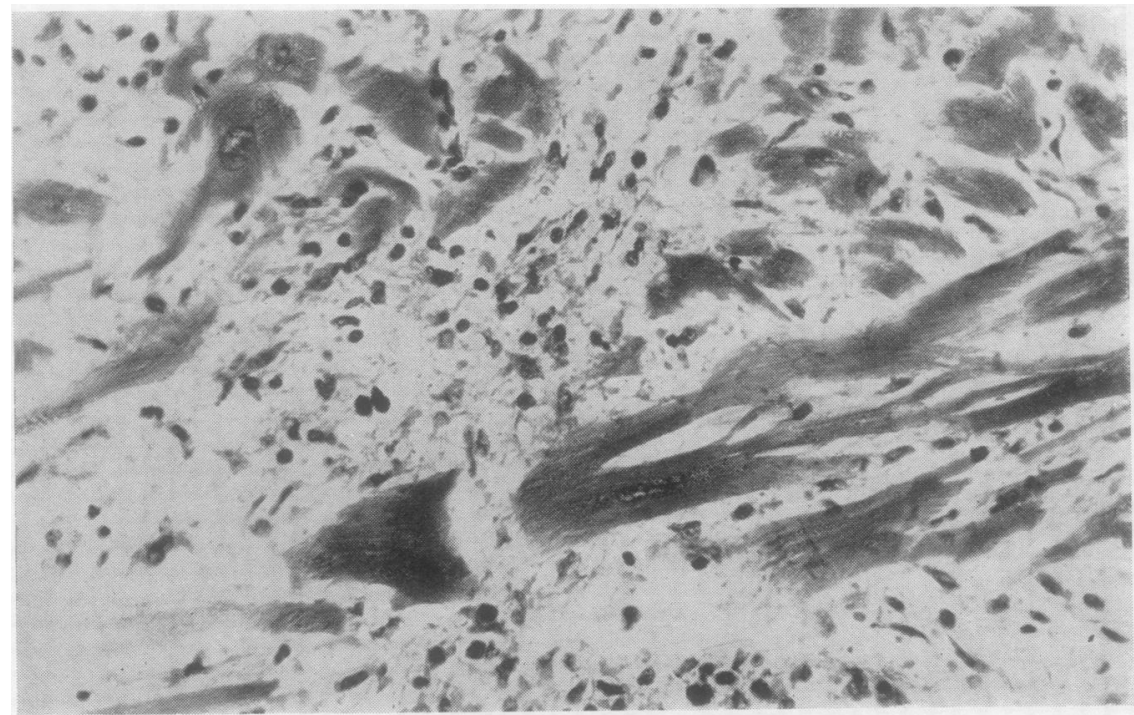

FIG. 7.-Myocardium showing cellular infiltration togother with degeneration of myocardial fibres. Stained by haematoxylin and eosin $(\times 240)$.

dilatation, and the sinusoids contain a large number of multinucleate giant cells, together with histiocytes and lymphocytes. The cytoplasm of some of the giant cells appears foamy.
Spleen.-The Malpighian corpuscles are frequently atrophic, contrasting with the cellular pulp in which granulocytes and reticulum cells are plentiful. 


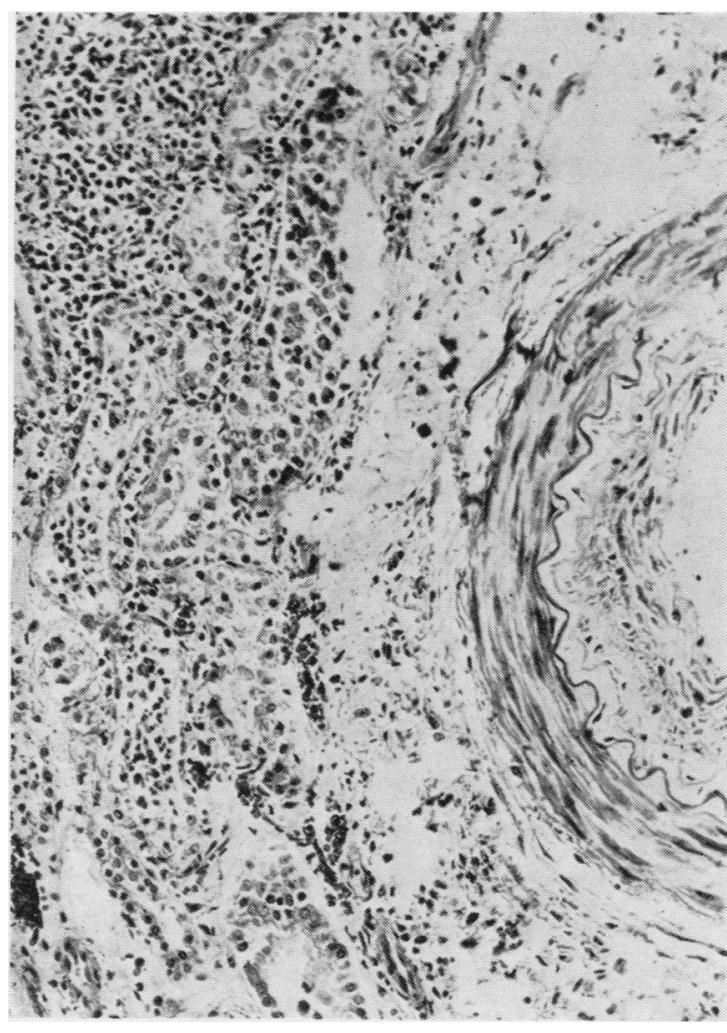

FIG. 8.-Kidney showing cellular infiltration of parenchyma and arterial intimal thickening. Stained by haematoxylin and eosin $(\times 140)$.

Heart.-The pericardial fat shows an occasional focus of chronic inflammatory cells, including giant cells, similar to that seen in the periadrenal tissue. The inflammatory reaction is in places associated with degeneration of fatty tissue leading to the formation of "foam" cells. A small artery in the fat adjacent to the myocardium is cuffed by this inflammatory exudate, and shows slight fibrin deposition on the intimal surface (Fig. 6). The visceral pericardial lining appears normal. There is a patchy cellular infiltration of the myocardium. The inflammatory cells lie sometimes between the muscle fibres, which are here in varying stages of degeneration (Fig. 7). The cells are occasionally collected in the paravascular connective tissue in a manner reminiscent of Aschoff nodes. No intravascular thrombi have been observed.

Kidneys.-Focal collections of inflammatory cells similar to those already described are present in the cortex, medulla, and peripelvic tissue of the kidney. Some of these cells are in relation to arteries which show intimal thickening (Fig. 8).
No intravascular thrombus, arteriolar necrosis, or thickening has been identified. The majority of glomeruli appear normal, though one shows capsular crescent formation.

Liver.-There is a slight increase of fibrous tissue in the portal tracts which are infiltrated by histiocytes and other chronic inflammatory cells in small numbers.

Duodenum. - Ectopic pancreatic tissue is present in the duodenal wall (the grey plaque noted macroscopically). There is a shallow inflammatory ulcer of the mucous membrane, and the pleomorphic inflammatory cellular reaction described for the periadrenal tissue extends here into the submucosa. A vein in this situation shows a fibrin lining to its intima, and an adjacent artery has its lumen nearly obliterated by intimal fibrous proliferation.

Pancreas.-There is advanced autolysis. An occasional collection of chronic inflammatory cells is present in the adjacent fat.

Lungs.-The lungs are congested, and tubercles are present in the sections taken from the left lower lobe. Some appear inactive, but one has cavitated and shows slight endothelioid palisading of its wall, and another solid tubercle shows similar slight palisading.

\section{Discussion}

Acute adrenal failure in the adult may be the manifestation of an Addisonian crisis or, less commonly, be due to bilateral adrenal haemorrhage. The latter change is usually associated with local infection, septicaemia, neoplasm, or trauma ; only a few cases have been reported as having no obvious precipitating factor. Berte (1953) reviewed the literature and could find only 17 such cases where haemorrhages occurred into both adrenals. On each occasion the haemorrhage into the glands was gross, causing disorganization of their structure: thrombosis of the adrenal veins was present in seven of the cases. Recently Plaut (1955) looked for adrenal cortical necrosis in 129 unselected necropsies of adult males, and found the change present focally in 11 . In seven of these the adrenal veins contained thrombi, but there was never any abnormality in the periadrenal arteries or arterioles. Plaut found no significant correlation of the necroses with the ages of the patients or their clinical features. It appears that the picture of bilateral and extensive anaemic infarction of the adrenals is distinctly rare.

The case under review differs from those studied by Berte in that the picture was one of infarction rather than haemorrhage and the necrosis was 
far more complete than in any of the adrenals examined by Plaut. The absence of major adrenal haemorrhage, together with the maintenance of a macroscopically normal glandular outline, the involvement of medulla as well as cortex and the presence of a widespread abnormality of periadrenal arteries, make it seem certain that the adrenal necrosis was in fact the result of a shutting down of arterial supply. However, the complex arterial system of the gland with the numerous small vessels of supply arising from more than one major artery (Anson, Cauldwell, Pick, and Beaton, 1947) makes it unlikely that the infarction could have been due to embolism or thrombosis, and indeed such features were not seen in the many sections examined. Vascular spasm remains the only reasonable alternative explanation for the phenomena observed.

The adrenal necrosis formed part of a widespread systemic disorder which included vascular disease, inflammatory cell infiltration of fatty tissue, and focal parenchymatous inflammatory cell infiltration as the main features. It became evident from a review of the surgical intestinal and skin biopsy specimens that the lesions here arose as a result of the same pathological change.

The vascular lesions were observed in the periadrenal and perirenal tissues, the epicardial fat, and in the wall of the intestine. The most frequent changes were endovascular intimal thickening by a loose connective tissue, seen more frequently in arteries than veins, and the deposition of fibrin. The latter usually formed a lining to the intima, but in one or two arteries it was present in the wall, the arteries then showing intimal proliferation as well. A third change most evident in the periadrenal fatty tissue was one of necrosis of the wall, associated with inflammatory cell infiltration.

All these changes are those which are shared by polyarteritis nodosa and forms of disseminate arteritis, as Pagel (1951) and McLetchie and Gillis (1955) have shown, and it is clear that the prominent clinical features of intestinal perforation, multiple skin infarction, and finally adrenal insufficiency were all due to this vascular disorder.

The other major pathological change in this case was the widespread involvement of fatty connective tissue by a form of inflammatory reaction. Part of the inflammation could be ascribed to secondary infection in the bowel and a reaction to necrotic tissue in the region of the suprarenals. That this was not the whole story is indicated by the pleomorphic nature of the cellular exudate, consisting of lymphocytes, polymorphs, histio- cytes, and multinucleate giant cells, and by the fact that the focal changes seen in the fatty tissue were strikingly uniform, indicating that there was a basic change occurring in fat cells; also similar collections of cells were seen within the viscera, such as the kidney and heart. The pleomorphic nature of the cells calls for a consideration that a form of Hodgkin's disease was the basic pathological process, especially as some of the abdominal lymph nodes were involved. This seemed to be ruled out, because nowhere could the cellular change be ascribed to an autochthonous hyperplasia of reticulo-endothelial cells, the giant cells were not of Hodgkin type, and the changes in the lymph nodes seemed to be largely those of drainage and histiocytic activity.

The association of inflammation of fatty tissue with vascular change is well recognized in systemic nodular panniculitis (Weber Christian disease). Steinberg (1953) reviewed the literature on this subject and stressed that perivisceral adipose tissue is frequently involved and that periarteritis and intimal proliferation form a part of the essential pathological features. The present case is remarkable in that the vascular lesions were so marke and that they led to the unusual clinical features of infarction of gut, skin, and adrenals. The patho logical findings here appear to represent a morph logical linkage between disseminate endarteritis, polyarteritis, and systemic nodular panniculitis, ํํำ and suggest that they are merely different expres- $\mathbb{\perp}$ sions of one fundamental process.

No further light is thrown on the aetiology of $\frac{0}{3}$ these conditions, though sensitivity to antituberculous drugs could have been an initiating factor.

\section{Summary}

A case of adrenal insufficiency due to bilateral infarction of suprarenals is reported. Symptoms $\delta$ were also present due to infarction of small bowel $₹$ and skin. These lesions were associated histo-을 logically with systemic panniculitis and endarteritis. The suggestion is made that the under-o lying pathological process was an unusual manifestation of the so-called collagen disorders.

We are indebted to Mr. A. E. Clark for the photomicrographs.

\section{REFERENCES}

Anson, B. J., Cauldwell, E. W., Pick, J. W., and Beaton, L. E. (1947) Surg. Gynec. Obstet., 84, 313.

Berte, S. J. (1953). Ann. intern. Med., 38, 28.

McLetchie, N. G. B., and Gillis, D. A. (1955). Amer. J. clin. Path., $25,502$.

Pagel, W. (1951). Journal of Clinical Pathology, 4, 137.

Plaut, A. (1955). Amer. J. Path., 31, 93.

Steinberg, B. (1953). Ibid., 29, 1059. 